\title{
DIVISÃO SEXUAL DO TRABALHO E O TEMPO COTIDIANO DAS MULHERES DE BAIXA RENDA
}

\author{
Fernanda Sucupira*
}

\begin{abstract}
Resumo: Este artigo analisa as consequências da articulação entre trabalho remunerado e trabalho doméstico e familiar sobre os usos do tempo das mulheres de baixa renda. A partir de entrevistas qualitativas com trabalhadoras que vivem com seus companheiros e filhos na comunidade de Paraisópolis, foram analisadas as repercussões da divisão sexual do trabalho na vida cotidiana delas. Identificaram-se também as estratégias de resistência desenvolvidas para lidar com a dupla presença feminina. Os depoimentos mostram que o dia a dia está tomado por essa dupla carga de trabalho, sobrando pouco espaço para outras temporalidades sociais.
\end{abstract}

Palavras-chave: Usos do tempo; divisão sexual do trabalho; relações sociais de sexo; trabalho doméstico; dupla presença.

\section{Sexual division of labor and the low-income women's daily time}

Abstract: This paper analyses the effects on the time use of low-income women caused by the combination of paid work and domestic and care labor. A field research was conducted with female workers who live with their partners and children in the Paraisópolis community, in order to analyze the consequences of the sexual division of labor in their everyday life. It also identifies the resistance strategies they have developed to deal with the dual presence. The research reveals that their daily lives are covered by this double burden that leaves little room for other social temporalities.

Keywords: Time use; sexual division of labor; social relations of sex; domestic labor; double burden.

\footnotetext{
* Mestra em Sociologia pela Universidade Estadual de Campinas (Unicamp) e especialista em Gênero e Igualdade nas Políticas Públicas pela Universidad Autónoma de Barcelona (UAB). Recebido em: 31/10/2015 - Aceito em: 15/04/2016.
} 
Divisão sexual do trabalho e o tempo cotidiano...

\section{División sexual del trabajo y el tiempo cotidiano de las mujeres de baja renta}

Resumen: Este artículo analiza las consecuencias de la articulación entre trabajo remunerado y trabajo domestico y familiar sobre los usos del tiempo de las mujeres de baja renta. A partir de entrevistas cualitativas con trabajadoras que viven con sus compañeros e hijos en la comunidad de Paraisópolis, se analizaron las repercusiones de la división sexual del trabajo en su vida cotidiana. También se identificaron las estrategias de resistencia desarrolladas para hacer frente a la doble presencia. Las declaraciones muestran que su vida cotidiana está tomada por esta doble carga de trabajo, dejando poco espacio para otras temporalidades sociales.

Palavras clave: Usos del tiempo; división sexual del trabajo; relaciones sociales de sexo; trabajo doméstico; doble presencia.

\section{1 - Introdução}

Nas últimas décadas, as pesquisas de usos do tempo têm revelado uma distribuição bastante desigual do tempo entre homens e mulheres na vida cotidiana. Eles continuam se dedicando ao trabalho produtivo de maneira quase integral, enquanto elas se esforçam para articulá-lo com o trabalho reprodutivo, com todas as tarefas de antecipação, organização concreta e de coordenação entre diferentes tempos e lugares.

Essa dupla jornada de trabalho a que as mulheres estão submetidas vem sendo denunciada pelos movimentos feministas brasileiros e suas teóricas desde a década de 1970, como um fator chave para as desigualdades de gênero. Trata-se de uma importante barreira para o desenvolvimento profissional feminino, um elemento que gera sobrecarga na vida de muitas mulheres.

Tal fenômeno foi denominado pela socióloga italiana Laura Balbo, ainda no final da década de 1970, como "dupla presença" (doppia presenza), conceito teórico mobilizado no presente estudo. O termo busca evidenciar a realidade de uma dupla carga de trabalho, de intensidade redobrada, vivida sincronicamente em um mesmo espaço e tempo (Balbo, 1994). A dupla presença constitui uma figura historicamente nova, determinada pela soma de duas presenças parciais, meia presença no trabalho, meia 
presença na família, o que quase esgota para as mulheres qualquer possibilidade de outra dedicação a si mesmas, em termos de descanso, distração, reflexão, estudos. Segundo a autora (Balbo, 1994), os dados indicam em termos bastante dramáticos em que medida a dupla presença converte as mulheres em malabaristas, obrigadas a estabelecer um equilíbrio de tempo muito rígido. Uma presença que, embora em termos de horário possa se dividir em dois meios tempos, não se reparte de igual modo em termos de concentração e tensão. Para que essa fórmula funcione, implica total ausência de qualquer outro âmbito de interesse e de desempenho além desse duplo trabalho.

Neste estudo optou-se por utilizar o termo "dupla presença" para se referir a esse fenômeno, acrescentando, assim, sentidos à ideia de "dupla jornada", que pode pressupor a possibilidade efetiva de concretizá-la - sem evidenciar as lógicas temporais distintas que precisam ser manejadas simultaneamente pelas mulheres (CARRASQUER, 2009).

Trata-se, na realidade, de uma dupla presença e de uma dupla ausência, porque as mulheres estão e não estão em nenhum dos dois lugares ao mesmo tempo (Carrasco, 2003). Vivem em seu próprio corpo a enorme tensão que significa a sobreposição de tempos estreitamente conectados e imbricados, tempos de pessoas diferentes, de lugares diferentes, que se irrompem uns sobre os outros e que se enredam entre si (MÉDA, 2002). Sofrem o contínuo deslocamento de um espaço a outro, de características específicas da atividade familiar a horários e valores do trabalho assalariado. Por mais que muitas vezes queiram ser as responsáveis pelos afazeres domésticos e familiares, suportam a impossibilidade de se sentirem cômodas em um mundo construído de acordo com o modelo masculino, que lhes exige interiorizar tensões, tomar decisões e fazer escolhas que a maioria dos homens não precisa fazer (CARRASCO, 2003). Essas mulheres têm a sensação de lutar contra o relógio para cumprir as obrigações que ambos os lugares reclamam - e que em muitos casos elas também desejam cumprir. Considera-se uma dupla ausência porque dificilmente 
experimentam uma sensação de plena realização nesses dois âmbitos; ao contrário, a vida é uma maratona diária, um estresse, uma jornada interminável.

Pode-se dizer que a dupla presença é uma das consequências da atual divisão sexual do trabalho, outra categoria analítica fundamental na presente investigação, em especial na linha teórica desenvolvida pelas sociólogas Danièle Kergoat e Helena Hirata. Essa divisão das tarefas, de acordo com Kergoat (2009), pode variar muito no tempo e no espaço, mas tem sempre dois princípios organizativos: o da separação (existem trabalhos de homens e outros de mulheres) e o da hierarquização (um trabalho de homem tem mais valor que um de mulher). Tem por característica a destinação prioritária dos homens à esfera produtiva e das mulheres à esfera reprodutiva e, simultaneamente, a ocupação pelos homens das funções de forte valor social agregado (políticas, religiosas, militares). Nela, produção "vale" mais que reprodução, produção masculina "vale" mais que produção feminina, tanto em termos de valorização social quanto econômica. Essas diferenças constatadas entre atividades dos homens e das mulheres, no entanto, são construções sociais e não produto de um destino biológico.

A divisão sexual do trabalho é, nesse enfoque, a base material das relações sociais de sexo. É o que está em jogo nessas relações transversais entre homens e mulheres, entendidas como desiguais, hierarquizadas, assimétricas ou antagônicas, de exploração e de opressão, entre duas categorias de sexo socialmente construídas (HIRATA, 2002).

Além disso, as duas autoras afirmam que produção e reprodução são elementos indissociáveis: a exploração por meio do trabalho assalariado e a opressão do masculino sobre o feminino não podem ser separadas (HIRATA e KERGOAT, 2003). Não é possível isolar o trabalho doméstico do trabalho assalariado na sociedade capitalista, ainda que ela seja construída sobre uma falsa separação dos lugares e dos tempos de produção e de reprodução. As relações de sexo e as relações de classe, portanto, são coextensivas, isto é, são conceitos que se sobrepõem parcialmente, que se interpenetram, 
se imbricam, e não simplesmente que se recortam ou se articulam (HIRATA e KERGOAT, 2002 e KERGOAT, 2009).

Desse modo, a persistência das desigualdades de gênero em âmbito laboral se explica, em grande medida, pela sobrecarga de trabalho reprodutivo a que as mulheres estão submetidas. As recentes pesquisas brasileiras sobre os usos do tempo mostram uma grande desigualdade na distribuição do tempo de trabalho profissional e de trabalho doméstico e familiar entre homens e mulheres.

De acordo com os dados da PNAD de 2009, os homens gastavam em média 10,5 horas por semana em atividades domésticas e as mulheres, 26,6 horas. Considerando apenas a população ocupada, eles despendiam 9,5 e elas 22 horas semanais. As mulheres ocupadas trabalhavam menos horas em atividades remuneradas (em média 35,6 horas semanais no mercado contra 42,9 dos homens), mas, levando em conta o tempo total despendido em atividades produtivas e reprodutivas, conclui-se que, em 2009, os homens ocupados gastavam em média 52,4 horas semanais, enquanto as mulheres ocupadas se dedicavam mais horas por semana ao trabalho em geral, consagrando em média 57,6 horas (IPEA, 2012). Esses dados confirmam que a carga total de trabalho é geralmente maior para as mulheres do que para os homens, mesmo que elas tenham jornadas produtivas mais curtas, o que significa que realizam longas jornadas de trabalho gratuito e sem reconhecimento social.

Ainda segundo o levantamento do IPEA (2012), não importa se as mulheres possuem renda alta, se são consideradas chefes de família, se estão ocupadas; em todos os casos elas sempre gastam mais tempo com afazeres domésticos do que os homens que estão nas mesmas posições. Mais impressionante ainda é o fato de que elas gastam mais tempo nessas atividades mesmo quando comparadas aos homens nas situações opostas: os de baixa renda, os considerados cônjuges e os desocupados. As mulheres ocupadas, por exemplo, gastam sete horas a menos por semana nas tarefas domésticas que as desocupadas, mas ainda se dedicam quase dez horas a mais a esse trabalho do que os homens desocupados. 
Por sua expressividade para revelar essas desigualdades de gênero na vida cotidiana, o tempo como categoria analítica também é um dos conceitos que permeia esta pesquisa. Não como um dado da natureza ou uma realidade objetiva, fora do controle humano, mas como uma construção social (ELIAS, 1998) e um elemento importante das relações de poder, algo que pode e deve ser transformado.

Nos últimos anos, tem sido realizada uma série de pesquisas sobre os usos do tempo no Brasil, para estudar como se organiza a vida cotidiana na nossa sociedade, analisar a configuração temporal das desigualdades e servir de subsídio para políticas públicas que promovam o bem-estar da população e a igualdade de gênero. No entanto, cada vez mais se constata que essas pesquisas mais gerais, e na maioria das vezes quantitativas, ainda precisam ser complementadas por estudos qualitativos, que se debrucem sobre grupos específicos e examinem as mudanças em curso nas temporalidades cotidianas.

Nesse sentido, tomando o quadro exposto anteriormente como ponto de partida, o presente estudo busca investigar empiricamente os efeitos de tal situação sobre um dos grupos mais afetados por essa sobrecarga, de acordo com as pesquisas de usos do tempo já realizadas no Brasil: mulheres urbanas de baixa renda, inseridas no mercado de trabalho, que vivem com seus cônjuges e com pelo menos um filho de até 14 anos. O objetivo desta investigação é, portanto, qualificar os estudos de usos do tempo no que se refere a essa parcela da população, para entender as mudanças em curso e as permanências, e analisar a evolução dos comportamentos influenciados pela divisão sexual do trabalho e pela sobrecarga gerada pela dupla presença dentro desse grupo. Por mais que esse seja um âmbito resistente a mudanças, isto é, uma configuração que persiste ao longo das décadas, é imprescindível que continue sendo investigado para compreender suas sutis transformações. 


\section{2 - Metodologia}

A presente pesquisa foi realizada na comunidade de Paraisópolis, considerada a favela mais populosa da cidade de São Paulo, com mais de 42 mil habitantes (IBGE, 2011). De julho de 2012 a maio de 2013 foram feitas entrevistas qualitativas semidirigidas e aprofundadas com 13 mulheres moradoras de Paraisópolis, de 22 a 49 anos, que viviam com seus companheiros e com pelo menos um filho de até 14 anos no mesmo domicílio, inseridas no mercado de trabalho, e com renda familiar inferior a cinco salários mínimos. Um perfil de mulheres que, de acordo com as recentes pesquisas brasileiras de usos do tempo, estão entre as mais afetadas pela sobrecarga de trabalho produtivo e reprodutivo.

As entrevistadas tinham de um a quatro filhos e a idade deles variava entre cinco meses e 17 anos, mas todas elas tinham ao menos um filho de até 14 anos vivendo em casa. Oito delas tinham um filho de até três anos, idade que exige mais cuidados. Apenas três eram casadas oficialmente, e as outras dez viviam em união estável com o companheiro. A escolaridade delas ia do segundo ano do ensino fundamental ao ensino superior incompleto. Cinco delas não haviam passado do primeiro ciclo do ensino fundamental, seis haviam concluído o ensino médio e duas estavam no ensino superior.

Em relação ao trabalho remunerado, a maior parte se concentrava em ocupações de trabalho reprodutivo (cozinheiras, faxineiras e trabalhadoras domésticas gerais). Além disso, também foram entrevistadas três auxiliares administrativas, uma professora, uma auxiliar de serviços gerais e uma locutora de rádio. Duas delas estavam desempregadas no momento da entrevista e uma estava no intervalo entre um emprego doméstico e outro. A renda familiar mensal variava entre $R \$ 900$ e $R \$ 3$ mil. Sete delas declararam renda familiar inferior a $R \$ 2$ mil e seis entre $R \$ 2,1 \mathrm{mil}$ e R\$ 3 mil. Em relação às atividades profissionais, as entrevistadas que estavam empregadas trabalhavam de forma remunerada de 10 a 48 horas por semana. Duas delas trabalhavam menos de 20 
Divisão sexual do trabalho e o tempo cotidiano...

horas semanais (19 e 10 horas) e quatro excediam o limite legal de 44 horas.

\section{3 - Resultados da pesquisa}

O presente estudo revela que algumas questões permanecem imutáveis há décadas, mas também fornece pistas a respeito de transformações que podem estar se iniciando. Os depoimentos analisados nesta investigação mostram que a vida cotidiana das mulheres em questão está tomada pelos tempos de trabalho, sejam eles gratuitos ou remunerados, em casa ou fora dela, sobrando pouco espaço para outras temporalidades sociais. Tempos que se sobrepõem e se opõem, que conflitam entre si, em uma rotina exaustiva e exasperante. A coextensividade (KERGOAT, 2010) de relações sociais de sexo e de classe desfavoráveis provocam efeitos perversos na vida cotidiana dessas mulheres, como se verá a seguir.

\section{1 - Falta de tempo}

Destacou-se a absoluta falta de tempo da maioria das entrevistadas para se dedicar a outras atividades que não fossem as profissionais ou as domésticas e familiares. Entre o trabalho remunerado, os afazeres da casa, o cuidado dos filhos, e o deslocamento entre esses espaços, sobrava pouco ou nenhum tempo para as demais esferas da vida cotidiana. Elas afirmaram faltar tempo principalmente para estudar, cuidar delas mesmas, sair para passear, passar mais tempo com os filhos, e para conviver com outros familiares, amigos e com o marido. Atividades esportivas, políticas, religiosas, culturais ou comunitárias quase nunca faziam parte do dia a dia dessas mulheres. Os dias de folga, em geral sábados e domingos, eram reservados especialmente para a realização de atividades domésticas que haviam se acumulado ao longo da semana, como lavar e passar roupa, fazer a faxina e pequenos consertos, e também para passar mais tempo com os 
filhos. No cotidiano das entrevistadas, eram raros os momentos de efetivo relaxamento ou de lazer.

Nos depoimentos, foi possível constatar o elevado grau de heteronomia dos tempos femininos, tanto relacionada ao trabalho remunerado quanto ao doméstico e familiar. Isso faz com que elas vivam um cotidiano quase exclusivamente guiado pelas necessidades dos outros, sejam eles seus empregadores ou seus familiares, uma vida limitada e restrita a certas atividades rotineiras, na qual elas não podem decidir como usar seu tempo:

\begin{abstract}
“Eu não voltei a estudar por causa da minha filha pequena. Porque a mais velha estuda à noite, tá terminando o terceiro colegial, né? Então o pai delas mesmo não deixa eu estudar, menina, por causa da outra, por causa da mais nova. Ele fala, a D. sai pro estudo, aí vai você, já fica a semana toda, o dia todo fora da menina, de noite chega e só vê ela uma horinha e vai pro estudo, e ele não concordou. Mas tenho vontade, sim." (Marilda, 39 anos, trabalhadora doméstica, 2 filhas, de 16 e de 7 anos).
\end{abstract}

Ou seja, Marilda, que havia cursado somente até o terceiro ano do ensino fundamental, tinha o desejo de voltar a estudar, mas ainda não havia retornado à escola porque o ex-marido não queria que ela ficasse longe da filha pequena. Ele considerava que essa era uma responsabilidade exclusivamente dela, e por esse motivo não permitia que ela dedicasse menos tempo à filha deles do que ele considerava adequado, ainda que fosse muito maior do que o que ele próprio dedicava a ela. Mesmo morando em casas separadas, e ela já estando com um novo companheiro, ele exercia uma relação de poder sobre ela a ponto de impedi-la de estudar, de controlar seus usos do tempo cotidiano. 


\section{2 - Sobrecarga de trabalho}

O principal eixo das desigualdades entre homens e mulheres nos usos do tempo cotidiano encontra-se no trabalho doméstico e familiar, historicamente realizado por elas, cujo objetivo é o cuidado da vida e o bem-estar das pessoas. Significa multiplicidade de tarefas, sobreposição de tempos, simultaneidade e acúmulo de atividades. Por ser ao mesmo tempo imprevisível e rígido, exige disponibilidade permanente do tempo das mulheres para o resto das pessoas que fazem parte da casa (CHABAUD-RYCHTER Et al, 1985).

Quanto ao trabalho doméstico e familiar, a jornada das entrevistadas se mostrou bastante extensa e muito superior à de seus maridos. Pelos depoimentos, nota-se que o trabalho doméstico e familiar preenchia praticamente todos os momentos ao longo da semana que não estavam ocupados pelo trabalho profissional ou pelo sono, em uma atividade considerada interminável. Com isso, pode-se observar que as tarefas domésticas e familiares não possuem um volume fixo ou definido, pelo contrário, vão se expandindo de acordo com a quantidade de tempo disponível das mulheres, podendo chegar a uma jornada de mais de 40 horas de segunda a sexta-feira.

Vários depoimentos mostraram uma evidente sobrecarga de trabalho vivenciada pelas entrevistadas em seu cotidiano. Era frequente entre elas a sensação de que a vida é um trabalho interminável, de que suas rotinas são enlouquecedoras, de que é impossível fazer tudo que lhes é exigido dentro e fora de casa. Essa sensação de que o tempo não é suficiente para todos os afazeres que lhes são atribuídos é algo recorrente entre homens e mulheres hoje em dia, visto que estão em curso formas de intensificação do trabalho e de extensão do tempo laboral. No entanto, no caso das mulheres, essa sensação gera ainda mais tensões e angústias no dia a dia, já que o trabalho doméstico e familiar tem um caráter circular e infinito. 
“Fico tensa, porque acaba se estressando, né. Você tenta fazer tudo e às vezes nem dá tempo de você fazer tudo. Quando você vai voltar pra fazer outra coisa, já tem que fazer tudo de novo. É complicado. Nunca termina, nunca. Parece uma bola que fica girando, girando, girando e você nunca termina de ver qual é o lado dela." (Lia, 32 anos, cozinheira, 3 filhos, de 15, 13 e 8 anos)

Uma das entrevistadas sequer queria que algo mudasse para que ela tivesse mais tempo disponível, por considerar que esse tempo também precisaria ser dedicado ao trabalho doméstico e familiar:

"Ai, tá bom. Se não seria mais passar roupa, mais limpar a casa. Não, tá bom, tá ótimo. Não sinto falta de ter mais tempo." (Ana Flávia, 34 anos, faxineira diarista, 1 filha de 11 meses).

Esse sentimento manifestado pela entrevistada evidencia o caráter infinito e elástico das atividades domésticas e de cuidados. A sensação que ela tem é de que esses afazeres ocupam todo o seu tempo livre e poderiam se expandir por muito mais horas.

A sobrecarga de trabalho gerada pela dupla presença tem consequências para a saúde e o bem-estar dessas mulheres, que se esforçam para enfrentar as tensões de dois mundos contraditórios. Não era raro que elas expressassem nas entrevistas um desejo de fugir dessa rotina estressante, de abandonar aquilo que se viam obrigadas a fazer no dia a dia, de desistir de tentar conciliar esses dois mundos inconciliáveis.

“É muito corrido. Imagina: três homens dentro de casa, uma bebê e eu só. Então você imagina como é a minha vida. Às vezes me dá vontade de fechar tudo e sair." (Miriam, 33 anos, auxiliar de serviços gerais, 2 filhos, de 17 anos e de 9 meses. Também estava morando com ela o irmão de 16 anos). 


\section{3. - Influências na trajetória profissional}

Assim como em outras pesquisas anteriores (entre elas Bruschini e Ricoldi, 2008), constatou-se que esses afazeres domésticos de atribuição quase exclusivamente feminina influenciam de forma bastante negativa a trajetória profissional delas, seja pela intermitência que adquire, pelo elevado absenteísmo ou por terem que aceitar trabalhos mais precários ou menos desejáveis, que possibilitem a articulação entre as duas esferas.

Algumas disseram que de fato "preferiam" ser as responsáveis pelo cuidado das crianças, por exemplo, por serem supostamente mais habilidosas para isso ou por ficarem mais preocupadas com elas, características atribuídas às mulheres, mas socialmente construídas. Outras, no entanto, questionam essa obrigação exclusivamente feminina, percebendo-a como limitante para sua própria trajetória profissional:

\footnotetext{
"Às vezes eu mesma fico me perguntando. Tem coisa que ele poderia fazer, e ele não corre atrás, sabe assim? Então por que é que um dia eu tenho que faltar no trabalho pra levar meu filho no médico e ele não pode? Então tem coisa que eu também não sei, tudo tem que ser eu mesmo." (Lucimar, 32 anos, trabalhadora doméstica, 2 filhos, de 5 e de 3 anos).
}

Entre as entrevistadas para a presente pesquisa, a sobrecarga gerada pela soma dos tempos de trabalho profissional e de trabalho doméstico e familiar, com as contradições inerentes a ela, resultava em períodos de estresse bastante agudos, que faziam com que algumas delas pensassem seriamente em parar de trabalhar. Muitas queriam dedicar mais tempo para seus filhos e cuidar melhor da casa, mas nem sempre podiam concretizar esse desejo. Na maior parte das vezes, acabavam desistindo dessa ideia por outros motivos, como sua importante contribuição para o orçamento familiar, o desejo de autonomia financeira ou mesmo de que suas vidas não se restringissem ao âmbito doméstico. Em 
alguns casos, porém, elas haviam deixado o trabalho por um período, para cuidar dos filhos pequenos, ou haviam reduzido sua carga horária, por mais que algumas não desejassem fazê-lo.

\begin{abstract}
"Quando ele nasceu e eu tive que sair da minha patroa, eu acho que eu fiquei até meio depressiva. Porque eu nunca fiquei desempregada, assim, muito tempo. E eu fiquei porque eu quis mesmo, mas foi opção minha. Só que eu senti muito, assim, falta do dinheiro, da minha independência. (...) Eu senti muito, foi bem difícil. Então eu acho que eu tava ficando mais estressada em casa, mesmo dando conta de tudo, do que trabalhando e em casa. Eu conseguia fazer tudo, mas eu não tava feliz." (Lucimar, 32 anos, trabalhadora doméstica, 2 filhos, de 5 e de 3 anos).
\end{abstract}

Nota-se em muitas delas, no entanto, uma aversão à ideia de abandonar o trabalho profissional para se dedicar somente às tarefas domésticas e familiares. Ou seja, por mais que a dupla presença exija que elas absorvam tensões entre as exigências contraditórias dessas duas esferas, a maior parte delas não quer sair de tal situação por essa via, temendo o que poderia representar um recuo rumo aos papéis tradicionais de gênero.

Contudo, ao colocar a carreira e os rendimentos em segundo plano, diminuem a possibilidade de mudar a divisão dos afazeres domésticos e familiares em seus domicílios, tendo ainda que se dedicar a empregos pouco satisfatórios do ponto de vista pessoal e profissional.

\title{
3.4 - Estratégias para lidar com a dupla presença
}

Em face à resistência masculina para alterar a divisão sexual do trabalho em âmbito doméstico, os esforços femininos para articular trabalho profissional e trabalho doméstico e familiar, em última instância, constituem também uma estratégia de resistência encontrada pelas mulheres para cuidarem dos filhos e 
da casa e, ao mesmo tempo, se manterem no mercado de trabalho e assegurarem sua independência financeira, sua relativa autonomia e sua presença no mundo público.

Dentre as estratégias observadas nos depoimentos, podemos destacar: a formação de redes femininas de intercâmbio desses afazeres; a realização de uma multiplicidade de tarefas cotidianas, em sequência ou sobrepostas; a intensificação do ritmo de realização das atividades; o tensionamento das relações familiares para conseguir contribuições de outros integrantes da casa nos afazeres domésticos e de cuidados; a redução ou a flexibilização da jornada de trabalho remunerado; a preferência por trabalhar para empregadoras mulheres, que teoricamente compreenderiam melhor essas questões; a priorização de trabalhos perto do local de moradia; a diminuição das horas de sono, acentuando o cansaço diário.

Também foram identificadas estratégias que se valem da elasticidade do trabalho doméstico e familiar, já que essas atividades podem ser comprimidas ou estendidas, feitas com maior ou menor intensidade, com maior ou menor rigor, de acordo, entre outros fatores, com a disponibilidade de tempo, com a necessidade e urgência de cada uma dessas tarefas. Entre essas estratégias está o adiamento de tarefas que são consideradas prescindíveis, difíceis, cansativas, e que consomem muito tempo, como passar roupa; a redução do padrão de limpeza, que costuma ser bastante rigoroso nesses domicílios; a compra de eletrodomésticos para gastar menos tempo com os afazeres da casa. Uma economia que, no entanto, pode ser revertida em horário disponível para atender a novas demandas, por causa da relação de disponibilidade permanente entre as mulheres responsáveis pelo trabalho doméstico e as demais pessoas da família (Ávila, 2009).

\section{5 - Redes femininas de solidariedade}

A principal estratégia para conseguir articular esses dois âmbitos, sem dúvida, é a formação de redes femininas de solidariedade: a constituição de um grupo de mulheres que em 
determinados momentos possam substituí-las, remuneradamente ou não, em algumas tarefas, em especial nas de cuidado de crianças pequenas. Uma rede informal e precária, fundamental na vida dessas mulheres, que muitas vezes substitui o papel do Estado, o qual não oferece suficientes vagas nas creches públicas. Assim, a vida cotidiana exige que elas façam arranjos complexos e rigorosamente calculados para dar conta de organizar a rotina infantil e continuar trabalhando, ao passo que seus maridos não costumam ter que se preocupar com isso.

Elas substituem umas às outras nas atividades domésticas e de cuidado, transferem tarefas, intercambiam afazeres, compartilham responsabilidades entre elas, em uma intrincada trama de colaboradoras, contribuindo, assim, para manter esse trabalho como função do grupo social das mulheres. Nas palavras de Chabaud-Rychter et al (1985), todas as mulheres se encontram em um circuito de troca com outras mulheres no que se refere a essas atividades; homens e mulheres, por outro lado, não são intercambiáveis no cumprimento delas.

No caso da presente pesquisa, as responsáveis por esse suporte às trabalhadoras eram principalmente suas mães, mas também suas irmãs, cunhadas, filhas mais velhas, vizinhas ou outras cuidadoras remuneradas. Uma rede que engloba todo o coletivo feminino. Tendo ou não filhos, sendo jovem ou de idade avançada, trabalhando fora ou apenas em casa, quase nenhuma mulher consegue estar verdadeiramente à parte dela.

Como afirma Ávila (2009), esses arranjos entre mulheres funcionam como uma forma de resistência para liberar seu tempo do trabalho doméstico gratuito, para que possam ter acesso ao trabalho remunerado. São arranjos que atravessam as relações familiares, as diferentes faixas etárias e as relações comunitárias, que vão solapando o cotidiano das mulheres que fazem parte do mesmo grupo familiar. Uma teia muito imbricada, sem quase nenhum apoio de políticas sociais e sem uma participação masculina efetiva. Vale ressaltar que, ao mesmo tempo em que constitui uma estratégia de resistência feminina, essa prática 
aprofunda as desigualdades entre homens e mulheres, ao incluir todas elas nesse circuito de trocas e ao deixá-los de fora.

Quando acontece algum imprevisto e essas trabalhadoras precisam ficar até mais tarde no serviço, na maior parte das vezes elas também acionam essa rede de mulheres e articulam diferentes pessoas para conseguir reorganizar os arranjos costumeiros. São poucos os casos em que os homens são mobilizados para isso.

"Eu tenho que sair ligando. Eu ligo pra minha mãe, ligo pra moça que olha minha filha, ligo na escola do meu filho, porque como é próximo [do meu trabalho], eles liberam meu filho pra vir pra cá e ele fica aqui comigo, o mais velho, de sete anos." (Laura, 25 anos, auxiliar administrativa, 3 filhos, de 7 e 4 anos e de 5 meses).

A contribuição dessa rede de mulheres era tão fundamental na vida de algumas trabalhadoras entrevistadas que elas tinham um enorme temor de perdê-la de uma hora para outra. Caso isso viesse a acontecer, elas acreditavam que a desorganização de suas vidas seria enorme, podendo comprometer o trabalho remunerado.

\begin{abstract}
"Eu tenho que dar um jeito, e o jeito é as minhas cunhadas. Essa que tá olhando ele no momento, ela tá só de ajudante num salão de beleza, então é só final de semana. Então ela tá livre na semana. Aí se ela arrumar um serviço, aí eu tenho que me virar. Porque ela que tá me salvando um pouco. Sem ela, eu não sei nem o que fazer no momento. Eu fico meio perdida. Até um dia ela falou, eu vou numa entrevista, ai meu deus! O que que eu vou fazer, e agora? Aí eu fico meio perdida." (Lucimar, 32 anos, trabalhadora doméstica, 2 filhos, de 5 e de 3 anos).
\end{abstract}

No caso dessa entrevistada, quando seu segundo filho nasceu, ela também se viu obrigada a parar de trabalhar, porque não havia conseguido vaga para nenhum dos dois em creches 
públicas. Na época, seu salário era de 650 reais, e ela estava pagando ao todo 400 reais para uma mulher do bairro cuidar deles. Isso mostra a influência das relações desfavoráveis de classe em sua vida profissional.

No momento da entrevista, ela estava trabalhando como empregada doméstica, mas considerava que ainda pesava muito sobre seus rendimentos ter que pagar para a cunhada buscar o filho mais velho na escola e cuidar dele meio período. Ela havia mudado de emprego fazia pouco tempo justamente porque precisava de um salário maior para poder arcar com essas despesas de maneira que não comprometesse tanto sua renda.

Por mais que as mulheres estejam cada vez mais adentrando o mercado de trabalho e permanecendo nele ao longo de suas vidas, a atual organização da sociedade ainda exige que existam pessoas fora dos constrangimentos do tempo produtivo, o tempo dominante, para que a articulação entre trabalho profissional e trabalho doméstico e familiar seja possível para as trabalhadoras. Podem ser aposentadas ou desempregadas, donas de casa, jovens em idade escolar, ou pessoas dispostas a fazer o trabalho reprodutivo de forma remunerada, quase sempre com salários muito baixos.

A rotina das entrevistadas se constitui de constantes apelos, pedidos de ajuda, contínua prestação de favores, salvamentos, socorros. As destinatárias habituais dessas demandas são suas próprias mães, que configuram o principal recurso na articulação entre essas duas esferas para as mulheres de baixa renda, com poucos recursos para externalizar essas atividades de forma remunerada.

Parte das entrevistadas precisava contar com alguém para ficar com as crianças ao menos por meio período ou para levá-las e/ou buscá-las na escola. Todos esses custos representavam uma parcela significativa da renda familiar dos domicílios pesquisados. As entrevistadas pagavam de 100 reais, por meio período, a 250 reais, o período integral, por cada criança, para cuidadoras informais ou mesmo para pessoas da própria família que tomavam conta de seus filhos. 
Já o depoimento de outra entrevistada reitera a ideia de que a gratuidade do trabalho de cuidado está muitas vezes relacionada às mulheres, mas não necessariamente aos homens da família. Ela pagava uma senhora para cuidar do filho mais novo de cinco meses enquanto trabalhava, mas às vezes precisava recorrer a familiares para ficarem com suas três crianças. Quando os deixava com a mãe ou com a irmã, esse trabalho não era remunerado; quando precisava que o irmão cuidasse deles, no entanto, ela o pagava. Não sabia explicar a razão de tal disparidade.

\begin{abstract}
"Olha, quando eu preciso, minha família que... é minha mãe, é minha irmã. Uma hora fica com a minha mãe, outra hora fica com a minha irmã, outra hora eu pago meu irmão." (Laura, 25 anos, auxiliar administrativa, 3 filhos, de 7 e 4 anos e de 5 meses).
\end{abstract}

Fica claro nesse caso a concepção de que para as mulheres o trabalho doméstico e familiar é uma obrigação, enquanto para os homens, por não ser sua atribuição "natural", precisa ser remunerado. Enquanto o tempo feminino deve ser doado para os demais sem qualquer retribuição, o masculino é uma mercadoria preciosa, vale dinheiro, só está disponível para essas atividades em casos excepcionais.

\title{
3.6 - Participação masculina
}

A colaboração por parte dos maridos não constitui efetivamente uma estratégia para lidar com a dupla presença. Em geral, a participação masculina nessas atividades pode ser definida como uma "ajuda" marginal, pontual, circunstancial, complementar, opcional e pouco significativa, frente ao volume de trabalho que precisa ser realizado todos os dias para garantir o bem-estar das pessoas da casa. Raramente o trabalho doméstico e familiar é feito como obrigação primária deles, pelo contrário, sua cooperação é considerada como uma espécie de concessão, favor, 
auxílio ou benevolência em relação a suas mulheres, as verdadeiras responsáveis por essas tarefas.

\begin{abstract}
"Agora, depois que eu reclamei muito, ele começou a ajudar mais com as crianças. De dar banho, porque eu chego do trabalho numa correria danada, então ele às vezes dá banho, ajuda a dar o jantar, mas, assim, de fazer mesmo da casa ele não ajuda muito, não. Dá banho nos meninos, leva pra escola, assim, essas coisas até posso contar com ele, mesmo, mas nos afazeres da casa mesmo é mais difícil." (Lucimar, 32 anos, trabalhadora doméstica, 2 filhos, de 5 e de 3 anos).
\end{abstract}

Caso não consigam, não queiram ou não possam realizar essas atividades, os homens não encaram isso necessariamente como um problema ou uma falta da parte deles. Enquanto, no caso delas, qualquer impossibilidade de cumprir uma atividade doméstica ou familiar gera culpa, estresse, necessidade de encontrar outra pessoa para substituí-las, ou faz com que se sintam obrigadas a se desdobrar para "dar um jeito" de contornar qualquer obstáculo. Disso se conclui que a participação dos homens no trabalho doméstico e familiar não implica para eles as mesmas limitações temporais e espaciais que para as mulheres, isto é, a disponibilidade permanente para essas atividades continua sendo exclusivamente feminina.

A contribuição masculina costuma estar concentrada nos finais de semana e ocorrer em situações específicas, quando elas saem, quando estão muito ocupadas com outras tarefas domésticas, quando os pressionam, quando eles têm bastante tempo disponível. Entre as atividades mais comumente realizadas pelos homens, de acordo com o depoimento das entrevistadas, estão: cuidar de filhos e filhas, cozinhar, lavar a louça, fazer compras no mercado e realizar pequenos consertos. Eles podem escolher as que mais lhes agradam, enquanto elas têm que fazer todas as outras, já que não possuem recursos para externalizá-las. 
Pode-se dizer que nas últimas três décadas houve uma ligeira mudança da postura masculina frente a essas atividades, conforme se observa na comparação com pesquisas mais antigas como a de Bruschini (1990), em que os homens em geral praticamente não exerciam papel nenhum nesse âmbito, mesmo quando suas mulheres também trabalhavam de forma remunerada. Machado (2014), analisando uma pesquisa da SOS Corpo e Data Popular, identificou alguns sinais dessa mudança de comportamento, que podem ou não se confirmar futuramente. A pesquisa em questão trouxe um discreto indicativo de que os homens mais jovens são mais prestativos do que os mais velhos.

Os dados da PNAD revelam que de fato nas últimas duas décadas vem aumentando a porcentagem de homens que contribuem com os afazeres domésticos e familiares nos lares brasileiros, chegando a mais da metade. Se em 1992 apenas 35,8\% dos homens ocupados realizavam afazeres domésticos (IBGE, 2002), em 2006 esse percentual subiu para 52\% entre os que trabalhavam (BRUSCHINI e RICOLDI, 2010). Já representa uma parcela importante da população masculina, mas continua muito inferior à das mulheres ocupadas que se dedicam às atividades domésticas, a qual desde 1992 fica em torno de 90\%. A quantidade de horas gastas por eles com essas atividades também continua muito menor do que a das mulheres, como já vimos, evidenciando a persistência das desigualdades nesse âmbito.

Em grande medida, a cooperação masculina aparece como uma espécie de "último recurso" do qual elas lançam mão em momentos de apuro, de extrema sobrecarga, de imprevistos, quando precisam de ajuda urgente ou repentina. Ainda assim, em poucos casos essa colaboração é considerada irrelevante pelas mulheres. Por mais que não seja sistemática, a participação masculina é valorizada e reconhecida por elas, por aliviar uma pequena parte da carga de afazeres domésticos e de cuidado que conformam o cotidiano estressante dessas trabalhadoras.

Enquanto em 1970 somente 18\% das mulheres brasileiras trabalhavam, em 2009 essa taxa já chegava a 53\%, em um ritmo 
acelerado de crescimento ${ }^{1}$ (BRUSCHINI ET AL, 2011), ao passo que a masculina chegava a $72 \%$ no mesmo ano. Se antes a atividade feminina remunerada diminuía muito a partir dos 25 anos, como resultado do casamento e da maternidade, em 2009 o percentual de mulheres de 30 a 39 anos em atividade alcançou quase $75 \%$.

A sutil transformação da postura masculina em relação a esses afazeres é insuficiente e excessivamente lenta, incompatível com as mudanças sociais em curso nas últimas décadas - isto é, com a entrada massiva das mulheres no mundo produtivo, um mundo cada vez mais exigente em termos de disponibilidade temporal. Não se evidencia, portanto, que esteja em curso uma efetiva alteração do comportamento masculino rumo à corresponsabilidade; assim, a divisão sexual do trabalho doméstico e familiar mantém seu padrão.

\section{7 - Conflitos e tensões}

A obrigação imposta às mulheres de articular trabalho remunerado e trabalho doméstico e de cuidado não apenas gerava fortes tensões na vida cotidiana da maioria das entrevistadas, como também provocava brigas constantes entre os membros de suas famílias.

“Lá em casa tem que ser na base do grito mesmo. Porque eu tenho que mandar, não tem nada dividido, não é que todo mundo sabe e vai fazer o seu, não tem essa. Lá tem que mandar." (Miriam, 33 anos, auxiliar de serviços gerais, 2 filhos, de 17 anos e de 9 meses).

\footnotetext{
${ }^{1}$ É importante lembrar que parte desse aumento se deve à ampliação do conceito de trabalho adotado pelo IBGE a partir de 1992, quando passou a incluir atividades para o autoconsumo, a produção familiar e o trabalho doméstico remunerado, entre outras que até então não eram consideradas trabalho (Bruschini, 2000).
} 
Como em todos os domicílios estudados a responsabilidade por essas tarefas era atribuída a elas, e como quase sempre encontravam dificuldades de realizá-las sozinhas por também trabalharem fora, precisavam cobrar diariamente seus maridos e filhos para que colaborassem em âmbito doméstico. Algumas delas discordavam dessa divisão e batalhavam para alterá-la, ao menos um pouco, ou simplesmente buscavam ter uma rotina menos estressante, por meio da pressão pelo compartilhamento de mais tarefas.

\begin{abstract}
“Eu chego, pô, meu, faz alguma coisa, caramba. Tu não me conquistou desse jeito, me dando um monte de roupa suja pra lavar. (...) Ele fica olhando pra minha cara, você pirou? E eu, ainda não, mas se você continuar desse jeito, eu vou pirar, vou pirar legal, hein, você não vai gostar". (Rosalva, 30 anos, locutora de rádio, quatro filhos, de 12, 11, 7 e 5 anos)
\end{abstract}

São justamente as outras mulheres da casa, como as filhas mais velhas, as que mais sofrem cobranças, atitude que reproduz e cristaliza a divisão sexual do trabalho. Enquanto os meninos são pouco exigidos nesse âmbito e participam mais voluntariamente, as meninas são pressionadas a realizar tais afazeres e aos poucos são formadas para isso. Com as mulheres adentrando cada vez mais o mercado de trabalho e a crescente influência do discurso igualitário, o estresse e a fadiga causados pela dupla presença provocam em muitas delas um forte senso de injustiça. Diante da resistência masculina no que concerne à repartição dessas tarefas, aumentam as discussões conjugais, as reclamações e o questionamento dessa "obrigação" exclusivamente feminina, que elas percebem como limitante para sua própria trajetória profissional. No discurso das entrevistadas, nota-se a recorrência de algumas palavras ao tratar da divisão do trabalho doméstico e familiar em seus domicílios: elas "cobram", "exigem", "mandam", "brigam", "discutem", "reclamam", "descem das tamancas", "jogam na cara"; por isso, são consideradas "chatas", "implicantes", "loucas". 
A aparente ampliação dos conflitos pode ser interpretada como uma pista de que pode haver uma mudança em curso. A progressiva inconformidade feminina com a tradicional divisão sexual do trabalho doméstico e familiar resulta em fortes pressões sobre os privilégios masculinos, na tentativa de alterá-la.

Essa contestação, no entanto, nem sempre surte os efeitos desejados. Muitos maridos ficam completamente indiferentes a essas cobranças e discussões, e não é raro que as deixem falando sozinhas:

"Eu fico nervosa, ele é muito tranquilo. Acaba eu brigando com ele. Ele fica, ai, não quero brigar com você, vou sair. Aí ele sai. Ele não briga." (Lucimar, 32 anos, trabalhadora doméstica, 2 filhos, de 5 e de 3 anos)

Isso leva a pensar que, para eles, a divisão sexual do trabalho doméstico e familiar é um fato tão estabelecido que sequer é digno de debate ou de questionamento. Tal atitude masculina frente à argumentação de suas mulheres mostra uma clara relação de poder dentro dos casais, uma relação assimétrica entre homens e mulheres que nem precisa ser defendida e justificada por eles para continuar existindo, que se apoia na noção tradicional dos papéis que cada um deve exercer.

Algumas das entrevistadas, no entanto, consideravam que simplesmente não valia a pena discutir com seus maridos sobre essas questões. Segundo elas, essas brigas apenas contribuíam para aumentar o desgaste provocado pela dupla carga de trabalho e não surtiam o efeito desejado, já que eles não alteravam o comportamento em relação aos afazeres domésticos e familiares. Elas preferiam realizar por si próprias essas atividades, e assim aceitar a configuração tradicional da divisão sexual do trabalho doméstico e familiar, a enfrentar conflitos cotidianos com seus maridos. 


\section{4 - Considerações finais}

A divisão igualitária do trabalho doméstico e familiar entre homens e mulheres é um passo fundamental no sentido de eliminar as desigualdades de gênero. Contudo, o presente estudo mostra que não constituiria uma transformação suficiente para acabar com as dificuldades e tensões cotidianas geradas pela articulação entre vida profissional e familiar. Mesmo que homens e mulheres compartilhassem igualmente essas tarefas em casa, ainda haveria uma série de questões a serem solucionadas, principalmente no que diz respeito ao cuidado das crianças. Ainda mais em tempos em que o trabalho remunerado exige cada vez mais disponibilidade temporal das pessoas.

Na atual organização de nossa sociedade, e na ausência de políticas sociais nesse sentido, para que pais e mães trabalhem remuneradamente ainda é necessária a existência de pessoas fora dos constrangimentos do tempo produtivo - o tempo dominante. Em geral, são mulheres: aposentadas, donas de casa, desempregadas, adolescentes, que fazem parte da família ou da comunidade, e que realizam essas tarefas de forma gratuita ou recebendo parcas remunerações. A dependência em relação a essa ajuda feminina provoca uma sensação de insegurança e instabilidade em relação à permanência no trabalho remunerado para as mulheres de baixa renda, mas não para os homens.

Por isso, afirmamos aqui o caráter eminentemente político dos tempos individuais e sociais, e enfatizamos a necessidade de colocar essa questão no centro do debate público. Afinal, não se trata simplesmente de conflitos e dificuldades individuais ou familiares, mas de um assunto coletivo, que diz respeito a todos e todas. Atualmente, as soluções privadas escamoteiam a dimensão do problema e colocam sobre as mulheres a responsabilidade de conciliar o inconciliável, reforçando a tradicional divisão sexual do trabalho.

O papel do Estado nesse sentido é fundamental, por meio de políticas públicas que busquem mudar a organização dos tempos vigente nas sociedades urbanas e industriais, levando em conta o 
viés sexuado de seus usos no dia a dia. Cabe ao Estado aplicar medidas que promovam a igualdade de gênero e o bem-estar de homens e mulheres, reestruturando as temporalidades cotidianas em uma valorização da multiplicidade dos tempos sociais.

\section{5 - Referências bibliográficas}

ÁVILA, M. B. O tempo de trabalho das empregadas domésticas: tensões entre dominação/exploração e resistência. Recife: Ed. Universitária da UFPE, 2009.

BALBO, L. "La doble presencia”, in BORDERÍAS, C.; CARRASCO, C.; ALEMANY, C. Las mujeres y el trabajo: rupturas conceptuales. Barcelona-Madrid: Fuhem-Icaria, 1994, pp. 505-513.

BRUSCHINI, C. Mulher, casa e família: cotidiano nas camadas médias paulistanas. São Paulo: FCC e Vértice, 1990.

BRUSCHINI, C.; RICOLDI, A. Articulação trabalho e família: famílias urbanas de baixa renda e políticas de apoio às trabalhadoras. São Paulo: FCC/DPE, 2008.

- Revendo estereótipos: o papel dos homens no trabalho doméstico. São Paulo: FCC/DPE, 2010.

CARRASCO, C. “¿Conciliación? No, gracias. Hacia una nueva organización social", in AMOROSO, M. I. et al. Malabaristas de la vida: Mujeres, tiempos y trabajos. Barcelona: Icaria, 2003, p. 27-51.

CARRASQUER, Pilar. P. La doble presencia. El trabajo y el empleo femenino en las sociedades contemporáneas. Barcelona: Tese de doutorado da Universidad Autónoma de Barcelona, 2009.

CHABAUD-RYCHTER, D.; FOUGEYROLLAS-SCHWEBEL, D.; SONTHONNAX, F. Espace et temps du travail domestique. Paris: Librairie des Méridiens, 1985.

ELIAS, N. Sobre o tempo. Rio de Janeiro: Jorge Zahar Ed., 1998. 
HIRATA, H.; KERGOAT, D. "Relações sociais de sexo e psicopatologia do trabalho", in HIRATA, H. Nova divisão sexual do trabalho? Um olhar voltado para a empresa e a sociedade. São Paulo: Boitempo, 2002, pp. 233-255.

"A divisão sexual do trabalho revisitada", in MARUANI, M.; HIRATA, H. (orgs.). As novas fronteiras da desigualdade: homens e mulheres no mercado de trabalho. São Paulo: Editora Senac São Paulo, 2003.

IBGE. "IBGE divulga indicadores sociais sobre a mulher". Comunicação Social, 07/03/2002. Disponível em: http://www. ibge.gov.br/home/presidencia/noticias/07032002mulher. shtm.

. Censo Demográfico 2010 - Aglomerados subnormais: Primeiros resultados. Rio de Janeiro: IBGE, 2011.

IPEA. "Trabalho para o mercado e trabalho para casa: persistentes desigualdades de gênero". Comunicados IPEA, n. 149, 23 de maio de 2012.

KERGOAT, D. "Divisão sexual do trabalho e relações sociais de sexo", in HIRATA, H. et al (orgs.). Dicionário Crítico do Feminismo. São Paulo: Editora UNESP, 2009, pp. 67-75.

. "Dinâmica e consubstancialidade das relações sociais", Novos estudos CEBRAP, n. 86, São Paulo, março de 2010.

MACHADO, M. "Trabalho remunerado e trabalho doméstico: conciliação?", in ÁVILA, M. B.; FERREIRA, V. (orgs.). Trabalho remunerado e trabalho doméstico no cotidiano das mulheres. Recife: SOS Corpo, 2014.

MÉDA, D. El Tiempo de las mujeres: conciliación entre vida familiar y profesional de hombres y mujeres. Madrid: Instituto de la Mujer, 2002. 